\title{
Western Blot Detection of Human Anti-Chikungunya Virus Antibody with Recombinant Envelope 2 Protein
}

\author{
Zhaoshou Yang ${ }^{1}$, Jihoo Lee ${ }^{2}$, Hye-Jin Ahn', Chom-Kyu Chong ${ }^{3}$, Ronaldo F. Dias ${ }^{4}$, Ho-Woo Nam ${ }^{1, *}$ \\ 'Department of Parasitology, College of Medicine, Catholic University of Korea, Seoul 06591; '2Department of Biochemistry, Chungbuk National \\ University, Cheongju 28644; ${ }^{3}$ Genbody Inc., Cheonan 31116, Korea; ${ }^{4}$ Bahia Farma Diagnostics, Cep 43.700-000, Simoes, Bahia, Brazil
}

\begin{abstract}
Chikungunya virus (CHIKV), a tropical pathogen, has re-emerged and has massive outbreaks abruptly all over the world. Containing many dominant epitopes, the envelope E2 protein of CHIKV has been explored for the vaccination or diagnosis. In the present study, the antigenicity of a recombinant expressed intrinsically disorder domain (IUD) of E2 was tested for the detection of the antibody against CHIKV through western blot method. The gene of the IUD of E2 was inserted into 2 different vectors and expressed as recombinant GST-E2 and recombinant MBP-E2 fusion protein, respectively. Two kinds of fusion proteins were tested with $30 \mathrm{CHIKV}$ patient sera and 30 normal sera, respectively. Both proteins were detected by 25 patients sera (83.3\%) and 1 normal serum (3.3\%). This test showed a relatively high sensitivity and very high specificity of the recombinant E2 proteins to be used as diagnostic antigens against CHIKV infection.
\end{abstract}

Key words: Chikungunya virus (CHIKV), envelope E2 protein, intrinsically unstructured domain (IUD), GST-E2, MBP-E2, western blot, patient sera

Chikungunya virus has re-emerged and caused unprecedented Chikungunya disease epidemics in Asia, Africa, Europe, and United States in the past decades [1-3]. Symptoms of CHIKV infection are characterized by fever, headache, incapacitating arthralgia, myalgia, skin rash, and severe synovitis [3,4]. Until now, several diagnostic tools [3] have been developed, which include PCR techniques to detect viral genomic material [2] and serodiagnostic techniques [4] identifying anti-CHKIV antibodies. A rapid diagnostic test kit has been developed [6]. In serological diagnosis, the CHIK virus-like particles (VLPs), envelope glycoproteins (E1, E2, and E3 proteins) $[4,7]$ and nonstructural proteins (nsP1, nsP3, and nsP4) $[3,8]$ have been well investigated. Among them, E2 is a prospective diagnostic candidate $[7,9]$ for the improved clinical diagnosis of CHIKV infection. Since the recombinant IUD fusion proteins show relatively higher sensitivity and solubility, the recombinant IUD [10] of E2 was researched in this study. The human antiCHIKV IgG antibody was tested by western blot.

Patients' sera were provided by Dr. Ronaldo F. Dias of the Ba-

- Received 11 November 2015, revised 13 January 2016, accepted 15 January 2016. *Corresponding author (howoo@catholic.ac.kr)

(c) 2016. Korean Society for Parasitology and Tropical Medicine

This is an Open Access article distributed under the terms of the Creative Commons Attribution Non-Commercial License (http://creativecommons.org/licenses/by-nc/3.0) which permits unrestricted non-commercial use, distribution, and reproduction in any

medium, provided the original work is properly cited. hia Farma Diagnostics (Simoes Filha, Bahia, Brazil) which were collected according to the "Bioethics and Security" and only unnamed samples described as numbers. The plasmid containing cDNA of E2 was provided by Genbody Inc. (Cheonan, Chungnam, Korea). Intrinsically unstructured region of E2 (GenBank no. KF925313.1) protein was predicted by IUPred server (http://iupred.enzim.hu/). The target fragment was amplified by PCR with designed primer sets as follows: for PMALc5X sense 5'-CCC CAT ATG TCC TTA ACA TGT TCT CCC CAC CGT CAG-3' and antisense 5'-CGG GAT CCG TCT GTA GTT ATT AGT CCT TCA TTT GAG CC-3', and for pGEX4T-1 sense 5'-CGG GAT CCC CGT CCT TAA CAT GTT CTC CCC-3' and antisense 5'-CGC TCG AGG TCT GTA GTT ATT AGT CCT TCA TTT GAG CC-3'. Digested fragments were ligated into pGEX4T-1 and pMAL-c5X vectors, respectively. The recombinant plasmids, pGEX-4T-1/E2 and pMAL-c5X/E2, were transformed into DH5a Escherichia coli. After confirmation of plasmids, the current plasmids were transformed into BL21(DE3)pLysS E. coli. Expression of glutathione S-transferase (GST)-E2 fusion proteins and maltose-binding protein (MBP)-E2 fusion proteins were induced at $0.5 \mathrm{mM}$ IPTG. Total lysates of $E$. coli were dissolved by SDS-PAGE and transferred onto nitrocellulose membranes (Whatman GmbH, Dassel, Germany). The membranes were blocked with 5\% skim milk (Difco Laboratories, Detroit, Michigan, USA) in PBS with 0.5\% Tween-20 (PBST). 

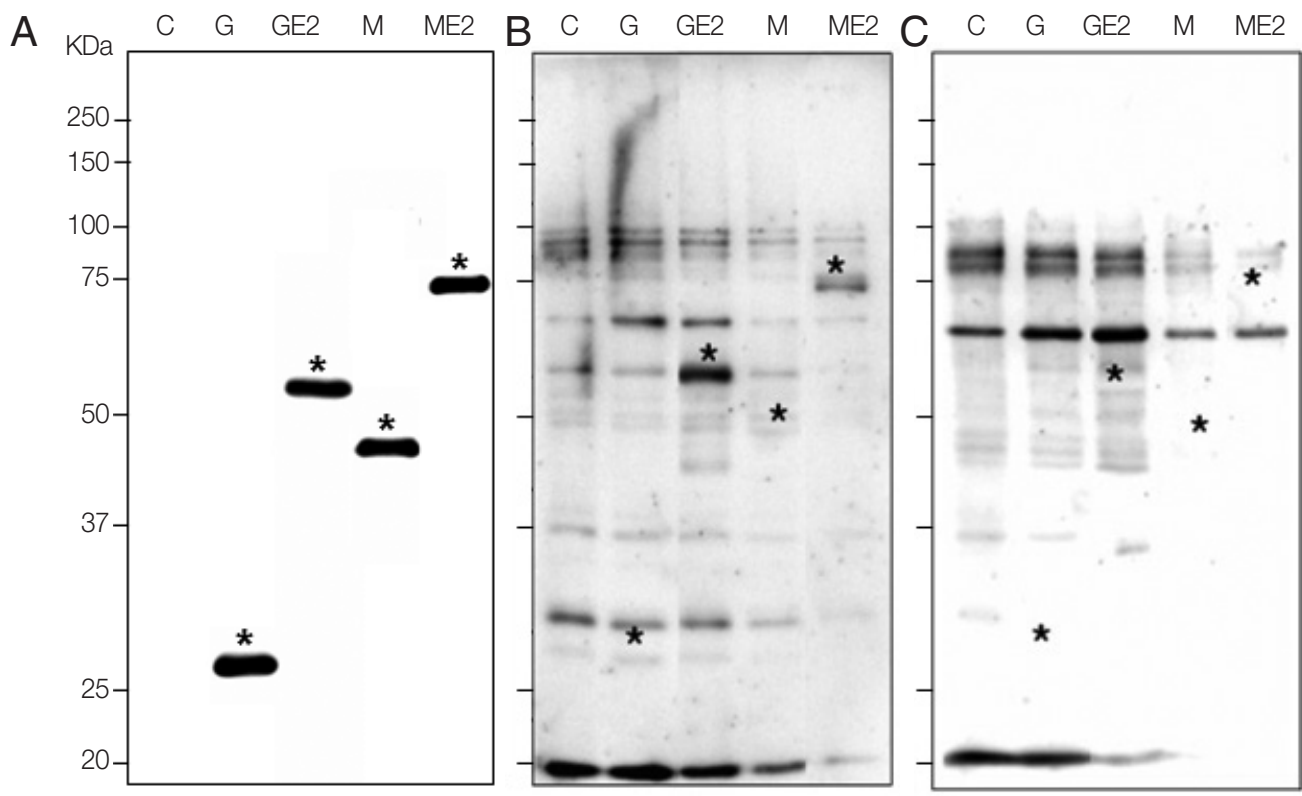

Fig. 1. Expression of recombinant $E 2$ antigens and reaction with patients or normal sera in western blot. (A) Confirmation of recombinant fusion proteins of E2 with GST and MBP. C, total lysate of non-induced BL21(DE3)pLysS E. coli; G, total lysate of E. coli transformed with pGEX-4T-1 vector after induction with IPTG as $26 \mathrm{kDa}$; GE2, total lysate of $E$. coli transformed with pGEX-4T-1/E2 plasmid after induction as $54 \mathrm{kDa}$; M, total lysate of $E$. coli transformed with pMAL-c5X vector after induction as $46 \mathrm{kDa}$; ME2, total lysate of $E$. coli transformed with pMAL-c5X/E2 plasmid after induction as $74 \mathrm{kDa}$, as marked with *, respectively. (B) Western blot with CHIKV patient serum which showed reactive bands as marked with asterisks. (C) Western blot with normal serum which showed no signal at the target MW.

Table 1. Reactivity of recombinant GST-E2 and MBP-E2 antigens against CHIKV patients' sera and normal sera

\begin{tabular}{lccccc}
\hline Sera & Control & GST & GST-E2 & MBP & MBP-E2 \\
\hline patients & $0 / 30$ & $0 / 30$ & $25 / 30(83.3 \%)$ & $0 / 30$ & $25 / 30(83.3 \%)$ \\
Normal & $0 / 30$ & $0 / 30$ & $1 / 30(3.3 \%)$ & $0 / 30$ & $1 / 30(3.3 \%)$ \\
\hline
\end{tabular}

After washing with PBST, the membrane was incubated with 1:100 diluted sera and then with HRP-conjugated anti-human IgG antibody (Sigma Aldrich, St. Louis, Missouri, USA). Chemiluminescence signals were detected with ECL Western blotting kit (Millipore Co., Billerica, Massachusetts, USA).

Both GST-E2 and MBP-E2 fusion proteins were well expressed with molecular weights of $54 \mathrm{kDa}$ and $74 \mathrm{kDa}$, respectively, by rabbit monoclonal GST antibody (Santa Cruz Biotechnology, Santa Cruz, California, USA) and mouse monoclonal MBP antibody (Cell Signaling Technology, Danvers, Colorado, USA). The second antibodies were horseradish peroxidase (HRP)-conjugated anti-rabbit antibody and HRP-conjugated anti-mouse antibody (Sigma Aldrich) (Fig. 1A). Our data identified a high sensitivity and high specificity of recombinant E2 fusion antigens. The sensitivity and specificity of 2 recombinant antigens were shown in Fig. $1 \mathrm{~B}$ and C. In western blot, 30 sera of CHIKV patients and 30 sera of normal humans were reacted. Among 30 patients' sera, both GST-E2 and MBPE2 were reacted with 25 sera based on the signals in western blots, which showed a high sensitivity of $83.3 \%$ with both recombinant fusion antigens. GST-E2 and MBP-E2 were reacted with 1 human normal serum among 30 normal sera, which demonstrated a high specificity (96.7\%) (Table 1).

In conclusion, the seroprevalence of anti-IUD of E2 IgG antibodies in patients infected with CHIKV was analyzed by western blot. Two kinds of tag fusion proteins were confirmed to find out the best recombinant antigen with high sensitivity, specificity, and solubility. These recombinant antigens can be used for further applications such as developing an RDT kit. Fortunately, GST-E2 expressed in E. coli is soluble, and MBP-E2 is very soluble to operate easily as promising recombinant antigens for the diagnosis of CHIKV infection.

\section{CONFLICT OF INTEREST}

We have no conflict of interest related to this work. 


\section{REFERENCES}

1. Burt FJ, Rolph MS, Rulli NE, Mahalingam S, Heise MT. Chikungunya: a re-emerging virus. Lancet 2012; 379: 662-671.

2. Parida MM, Santhosh SR, Dash PK, Tripathi NK, Lakshmi V, Mamidi N, Shrivastva A, Gupta N, Saxena P, Babu JP, Rao PV, Morita K. Rapid and real-time detection of Chikungunya virus by reverse transcription loop-mediated isothermal amplification assay. J Clin Microbiol 2007; 45: 351-357.

3. Kam YW, Pok KY, Eng KE, Tan LK, Kaur S, Lee WW, Leo YS, Ng LC, Ng LF. Sero-prevalence and cross-reactivity of chikungunya virus specific anti-E2EP3 antibodies in arbovirus-infected patients. PLoS Negl Trop Dis 2015; 9: e3445.

4. Dudha N, Rana J, Rajasekharan S, Gabrani R, Gupta A, Chaudhary VK, Gupta S. Host-pathogen interactome analysis of Chikungunya virus envelope proteins E1 and E2. Virus Genes 2015; 50: 200-209.

5. Goh LY, Kam YW, Metz SW, Hobson-Peters J, Prow NA, McCarthy S, Smith DW, Pijlman GP, Ng LF, Hall RA. A sensitive epitope-blocking ELISA for the detection of Chikungunya virus-specific antibodies in patients. J Virol Methods 2015; 222: 55-61.

6. Okabayashi T, Sasaki T, Masrinoul P, Chantawat N, Yoksan S, Nitatpattana N, Chusri S, Morales Vargas RE, Grandadam M,
Brey PT, Soegijanto S, Mulyantno KC, Churrotin S, Kotaki T, Faye O, Faye O, Sow A, Sall AA, Puiprom O, Chaichana P, Kurosu T, Kato S, Kosaka M, Ramasoota P, Ikuta K. Detection of chikungunya virus antigen by a novel rapid immunochromatographic test. J Clin Microbiol 2015; 53: 382-388.

7. Tripathi NK, Priya R, Shrivastava A. Production of recombinant Chikungunya virus envelope 2 protein in Escherichia coli. Appl Microbiol Biotechnol 2014; 98: 2461-2471.

8. Kumar S, Mamidi P, Kumar A, Basantray I, Bramha U, Dixit A, Maiti PK, Singh S, Suryawanshi AR, Chattopadhyay S, Chattopadhyay $\mathrm{S}$. Development of novel antibodies against non-structural proteins nsP1, nsP3 and nsP4 of chikungunya virus: potential use in basic research. Arch Virol 2015 (August 18).

9. Bhatnagar S, Kumar P, Mohan T, Verma P, Parida MM, Hoti SL, Rao DN. Evaluation of multiple antigenic peptides based on the Chikungunya E2 protein for improved serological diagnosis of infection. Viral Immunol 2015; 28: 107-112.

10. Song KJ, Yang Z, Chong CK, Kim JS, Lee KC, Kim TS, Nam HW. A rapid diagnostic test for toxoplasmosis using recombinant antigenic N-terminal half of SAG1 linked with intrinsically unstructured domain of gra2 protein. Korean J Parasitol 2013; 51: 503-510. 